This copy is for your personal, non-commercial use only.

If you wish to distribute this article to others, you can order high-quality copies for your colleagues, clients, or customers by clicking here.

Permission to republish or repurpose articles or portions of articles can be obtained by following the guidelines here.

The following resources related to this article are available online at www.sciencemag.org (this information is current as of September 27, 2012 ):

Updated information and services, including high-resolution figures, can be found in the online version of this article at:

http://www.sciencemag.org/content/337/6101/1492.full.html

A list of selected additional articles on the Science Web sites related to this article can be found at:

http://www.sciencemag.org/content/337/6101/1492.full.html\#related

This article cites $\mathbf{3 0}$ articles, 5 of which can be accessed free:

http://www.sciencemag.org/content/337/6101/1492.full.html\#ref-list-1

This article appears in the following subject collections:

Medicine, Diseases

http://www.sciencemag.org/cgi/collection/medicine 
36. D. ]. Selkoe, Nat. Med. 17, 1060 (2011).

37. N. T. Lautenschlager et al., JAMA 300, 1027 (2008).

38. K. A. Intlekofer, C. W. Cotman, Neurobiol. Dis., published online 4 July 2012);

39. C. Sattler, P. Toro, P. Schönknecht, ]. Schröder, Psychiatry Res. 196, 90 (2012).
40. S. M. Landau et al., Arch. Neurol. (2012).

41. S. A. Wolf et al., Biol. Psychiatry 60, 1314 (2006)

42. D. A. Costa et al., Neurobiol. Aging 28, 831 (2007).

43. H. X. Wang, A. Karp, B. Winblad, L. Fratiglioni, Am. J. Epidemiol. 155, 1081 (2002).

44. ]. Verghese et al., Neurology 66, 821 (2006).
Acknowledgments: The author serves on the board of directors of, and is a paid consultant for, Elan Corporation, plc, a biotechnology company that is developing therapies for neurodegenerative diseases, including $A D$.

10.1126/science.1228541

\title{
Changing Human Behavior to Prevent Disease: The Importance of Targeting Automatic Processes
}

\author{
Theresa M. Marteau, ${ }^{{ }^{*}}{ }^{*}$ Gareth J. Hollands, ${ }^{1}$ Paul C. Fletcher ${ }^{2}$
}

Much of the global burden of disease is associated with behaviors-overeating, smoking, excessive alcohol consumption, and physical inactivity - that people recognize as health-harming and yet continue to engage in, even when undesired consequences emerge. To date, interventions aimed at changing such behaviors have largely encouraged people to reflect on their behaviors. These approaches are often ineffectual, which is in keeping with the observation that much human behavior is automatic, cued by environmental stimuli, resulting in actions that are largely unaccompanied by conscious reflection. We propose that interventions targeting these automatic bases of behaviors may be more effective. We discuss specific interventions and suggest ways to determine whether and how interventions that target automatic processes can enhance global efforts to prevent disease.

A the 65th World Health Assembly held in Geneva in May 2012, health ministers pledged a $25 \%$ cut in premature deaths from the four most prevalent noncommunicable diseases - diabetes, cardiovascular disease, lung disease, and cancer-by 2025. Achieving this will require sizeable shifts in the population distribution of consumption of calories, tobacco, and alcohol, as well as increased levels of physical activity and fruit and vegetable consumption. But how might such changes in behavior be achieved? Hitherto, nonregulatory approaches to changing behaviors across individuals and populations have focused largely on using information to persuade people of the risks they face and the potential benefits of change, through clinics or public health campaigns, such as those aimed at increasing the consumption of fruit and vegetables or at reducing the consumption of alcohol. More recent variants of this approach include personalizing risk messages using the results of a wide array of biomarker tests, including blood glucose levels indicating an increased risk of diabetes and gene variants indicating an increased risk of heart disease. These approaches have had either modest or no effects on health-harming behaviors $(1,2)$.

We propose that the potential for informationbased interventions is fundamentally limited,

\footnotetext{
${ }^{1}$ Behaviour and Health Research Unit, Institute of Public Health, University of Cambridge, Cambridge CB2 OSR, UK. ${ }^{2}$ Department of Psychiatry, University of Cambridge, Cambridge CB2 OSR, UK.

*To whom correspondence should be addressed. E-mail: theresa.marteau@medschl.cam.ac.uk
}

given that it is based on a view of human behavior that is at odds with psychological and neuroscientific evidence that much human behavior is not actually driven by deliberation upon the consequences of actions, but is automatic, cued by stimuli in the environment, resulting in actions unaccompanied by conscious reflection (3).

\section{Flexibility Versus Efficiency: Understanding the Balance in Human Behavior}

Throughout our day, we shift between two broad categories of behavior $(4,5)$. On the one hand, we may act in a reflective manner, directing ourselves toward particular goals, aware of our motivations and actions and able to halt or modify them should the need arise. In other instances, we act without reflection, responding to our surroundings in complex ways while our thoughts may be far removed. Each of these types of behavior has its advantages and disadvantages. The former is goal-directed, flexible, and rational insofar as it is motivated by explicit beliefs and desires. But it is also slow, cumbersome, and metabolically costly, absorbing our attention and preventing other processing. It is especially inefficient when it comes to routine situations: Why would one wish to deliberate over each stage of a familiar route home? The latter behaviors, in their automaticity, have the advantage of capitalizing on the routine and the predictable, freeing us to devote our cognitive capacity to other matters while nevertheless engaging in complex and fruitful actions. However, in becoming divorced from awareness and reflection, these automatic behav- iors lose flexibility and may become out of touch with conscious desires, proceeding even when the consequences are unwanted. Thus, we may find ourselves taking the well-travelled route home when the original intention had been to call elsewhere.

Although it is usual to draw a complete distinction between these two broad categories of behavior, in fact they overlap and interact, with any given behavior consisting of a complex mixture of the two. Ideally, they would, and often do, complement each other, but they may also come into conflict. This is particularly so in the case of health-related behaviors, for which people often have competing goals (such as a pleasure goal of enjoying a cake versus a health goal of reducing weight). It is perhaps most useful to think of them in terms of a balance, with certain factors promoting the more reflective and others the more automatic behaviors. Thus, for example, engaging in a task that absorbs attention may shift us toward more automatic behavior. This is illustrated in an experiment showing that having to remember a long string of numbers made people more likely to select chocolate cake than fruit salad when presented with a forced choice in the middle of the experiment (6). Stress too can shift us from being rational and goal-directed to more automatic, responding to external stimuli and persisting in actions that are not ultimately helpful.

The above distinction is very relevant to established experimental work on habits, which are actions that occur in response to stimuli without necessarily bringing to mind the goal of that action. Habits are contrasted with goal-directed behavior and form one class of automatic behavior. They become established by repetition and routine, their emergence being marked by measurable changes in brain circuits (7). Although habits constitute an important class of automatic behavior, it is important to note that not all automatic behavior is habitual. For example, viewing a beer advertisement on television may result in the viewer going to the fridge for a beer without awareness of the

"Ninety-nine hundredths or, possibly, nine hundred and ninetynine thousandths of our activity is purely automatic and habitual, from our rising in the morning to our lying down each night."

William James (1899) 
link between the ad and her behavior (i.e., it is a behavior cued when the environmental cue elicits the goal or desire), but this need not be a habitual response to watching television. Additionally, automatic behavior can be goal-directed $(8-10)$. Finally, although automatic behaviors are generally considered to occur without awareness, automaticity is best considered as a continuum, with some automatic behaviors cued and enacted entirely outside of awareness (such as the mimicry of nonverbal behavior in social interactions), whereas for others, the cue and the ensuing behavior may be noticed while the causal link between the two occurs outside awareness [such as occurs in the priming effects on consumption of the advertising of food and alcohol $(11,12)]$.

The key point here is that environmental cues can elicit both habitual actions in the absence of a conscious desire (the hand that dips into the open biscuit tin), or they can automatically, perhaps unconsciously, bring to mind a desire. In both cases, the behavior that emerges can be considered automatic and unlikely to be susceptible to modifications aimed at rational, reflective thought. This account of human behavior helps explain why health-harming behaviors persist in the population and are so resistant to change. We argue that the time is right to examine whether interventions that target these automatic, unreflective processes can change behavior on a scale that will contribute to realizing the World Health Assembly's ambition.

\section{Changing Human Behavior}

Despite the work in brain and behavioral sciences demonstrating the dominance of automatic processes in guiding action, most interventions aimed at changing health-related behavior target reflective processes. At their simplest, these interventions entail providing information in an attempt to persuade people to change their behavior in, for example, mass media campaigns designed to increase the consumption of fruit and vegetables. At their more complex, they aim to impart skills to increase individuals' self-regulatory capacity to engage in healthier behavior, as found in stop smoking services and weight loss programs. Although the latter type of intervention can achieve sustained change in, for example, diet, physical activity, and smoking (13), their potential to change behavior on the scale needed to halt and reverse the rise in noncommunicable diseases is limited, because only a minority of those with the unhealthy behavior engage in such programs and, for those that do engage, the effect sizes achieved are modest (2). Such effect sizes are smallest for routine learned behaviors. This accords with observations that high levels of training and repetition in experimental animals produce behaviors that are persistent and insensitive to changed or devalued outcomes (14). The very highly trained rat will continue to press a

consider making the elevator a less appealing option by increasing the effort required to use it. For example, slowing down the speed at which elevator doors close, thus increasing the journey time, increases stair use (16). Similarly, altering the effort required to reach foods in a cafeteria salad bar (Fig. 1) by manipulating their proximity by only around 10 inches, can increase the selection of easier-toreach food options (17). Reducing the proximity and density of retail outlets for alcohol, tobacco, and junk food can also reduce purchasing and consumption (18).

Availability of options within environments. The availability of an option within a given environment increases the ease with which it can be used and thereby the likelihood of this. For example, commuters used the stairs nearly twice as much when there was only one ascending escalator available as an alternative to taking the stairs, as when there were two escalators (19). Increasing the number of healthier food and drink options in vending machines has also been shown to increase the likelihood that healthier choices will be selected (20).

lever for a drink even when that drink has been made bitter. It accords too with our everyday experience that highly routine behaviors, including what and when we eat, are difficult to change.

There are many such interventions that probably require little, if any, conscious engagement or target automatic processes to change healthrelated behaviors, and that could be implemented at the population level. We outline below some examples from laboratory and field experiments. These fall into two broad but overlapping categories: (i) those that alter a person's environment and (ii) those that aim to target automatic processes (and thereby how an individual responds to environmental cues).

(i) Altering environments to constrain behavior. Reflecting Tolman's law of least effort, which was based on observing rats taking the shortest path in a maze, altering the properties of objects or their space within physical environments can constrain or shape responses to make the least effortful course the most likely, without a need to prompt conscious deliberation (15).

Ease of effort. Taking the elevator rather than the stairs typically requires less effort on the part of the individual. To encourage the more physically active behavior of using the stairs, we can
Product design. The design of a product shapes our behavior in relation to it. Over time, many products central to health-related behavior have altered in ways that result in less energy expenditure and greater consumption. For example, 150 years ago, clerks worked at standing desks. The provision of modern equivalents in schools can result in pupils expending more calories (21). The size and shape of tableware, such as plates and drinking glasses, have also changed over the centuries, with both properties influencing eating and drinking behavior. For example, taller glasses resulted in less being poured and drunk than shorter, wider-bottomed glasses, although study participants perceived the opposite to be true (22).

(ii) Targeting automatic associative processes. We describe examples of interventions that deliberately target automatic processes to activate, inhibit, or alter existing associations or create new ones, so that individuals behave differently in reaction to environmental cues.

Activating or inhibiting existing associations. Priming is one mechanism to influence behavior outside awareness. It involves presenting a stimulus that activates or inhibits an associated mental representation (a concept, action, or goal). This alters the threshold for action and the likelihood 
of its expression given subsequent exposure to a relevant stimulus. For example, priming the concept of old age (by exposing participants to words such as "wrinkles" and "gray") led to participants walking more slowly when leaving the experiment (23). Priming effects have been demonstrated across a range of responses and stimuli, including the presentation of alcohol and snack food in advertisements. For example, children watching cartoons interspersed with food advertisements ate $45 \%$ more of the snacks made available to them (which did not appear in the advertisements) than children watching cartoons interspersed with advertisements for nonfood items. Adult consumption of snacks was also affected (11). Similarly, adults watching film clips that included scenes in which alcohol featured prominently, interspersed with advertisements for alcoholic beverages, selected more alcoholic beverages to drink afterward than did those exposed to either of these alone. Those exposed to film clips and advertisements that did not feature alcohol selected the fewest alcoholic beverages (12). In accordance with such findings, restricting marketing is considered one of the more potent interventions in reducing tobacco use, alcohol consumption, overweight, and obesity, particularly in children (24). The potential of using priming interventions to reduce consumption is promising (25) but little studied thus far.

Altering existing or creating new associations. Humans are generally predisposed to approach positive stimuli (those we anticipate as being rewarding) and avoid negative stimuli (those we anticipate as being unrewarding or even punishing). Products are frequently packaged with a variety of positive and negative associations, generating competing behavioral impulses. Increasing approaches toward healthier behaviors and products and the avoidance of less-healthy options involves increasing positive associations with the former and negative associations with the latter. So, for example, using fun terms to describe healthier foods increases the chances that children will eat them, as does putting cartoon characters on vegetables (26), whereas removing branded packaging of junk food and tobacco reduces the attractiveness of the products $(27,28)$.

The interventions described above may have additional benefits: Their delivery (for example, via a change in the physical environment) does not usually require complex systems or direct contact with people, thus allowing increased efficiency and decreased costs as compared with individually delivered interventions. They also have the potential to reduce health inequalities, because they do not rely on the communication and comprehension of complex information about health. The impact of interventions that involve providing persuasive information depends on recipients' literacy, numeracy, and cognitive control, which are generally poorer in those who are more deprived (29-31). In contrast, changes made to the physical environment largely bypass these processes, having the potential to shape behavior for all individuals who are exposed to that environment.

\section{Future Directions}

The interventions we have described are, in principle, scaleable to the population level, although uncertainty remains about whether they will be effective in changing behavior in populations living in complex environments and at a level needed to reduce the global burden of chronic disease. Several steps are needed to test this. First, we must identify which stimuli in which environments are most likely to achieve sustained healthy behaviors. For example, although the quantity and quality of space devoted to unhealthy and healthy products in a grocery store, as well as their packaging and marketing in and out of the store, will influence the relative healthfulness of the food bought, experiments are needed to determine the grocery store design that maximizes healthful purchasing (in contrast to current stores, which are designed to optimize profits, regardless of the healthfulness of the food purchased).

Second, it will be important to undertake a systematic synthesis of existing evidence to assess the processes that explain the impact of interventions targeting automatic processes. Automaticity remains an elusive concept, difficult to understand and identify (32). The formidable task of conceptually framing and synthesizing study findings is just beginning (33). Such syntheses have the potential to enrich understandings of basic brain processes that activate behavior, as well as to inform the designs of future environments, built and virtual, with a higher chance than existing ones of activating healthier behavior and inhibiting lesshealthy behavior on the scale needed to make a measurable impact on population health.

Third, there is scope for the development of new interventions. Individual-level interventions shown to be effective at changing behavior in laboratory and community settings might be adapted so that they can be delivered at the population level. These include computer-based evaluative conditioning procedures that weaken positive associations with potentially health-damaging products (34), training to inhibit behavioral impulses to engage in unhealthy behaviors (35), and the formation of intentions to implement a particular behavioral response upon encountering a particular cue (36). This latter approach would actually capitalize on our remarkable potential to develop automatic responses, in this case putting a positive automatic response in place of a harmful one.

Implementing interventions that target the automatic bases of health-damaging behaviors will require that certain philosophical, political, and economic barriers be overcome. These include the implied threat to our understanding of what it is to be human, given that the most-parsimonious models of behavior involve acknowledging that much of our behavior takes place outside of awareness. Furthermore, given the multitude of existing cues driving us toward health-harming behavior, it remains to be seen whether we can gain a toehold in an environment that is already exerting strong negative impacts on health. A further threat is posed to economies that are built on excessive consumption, because successful behavioral-based efforts to prevent disease would reduce the consumption of food, alcohol, and tobacco, as well as their transport by fossil fuels. Political and public wills need to be aligned for the successful enactment of interventions that reduce such consumption. Although the precise global strategies for achieving the World Health Assembly's laudable ambition are evolving, it is clear that behavioral and brain sciences have a role to play.

\section{References and Notes}

1. T. M. Marteau et al., Cochrane Database Syst. Rev. 2010 CD007275 (2010)

2. T. L. Webb, P. Sheeran, Psychol. Bull. 132, 249 (2006).

3. D. T. Neal, W. Wood, J. M. Quinn, Curr. Dir. Psychol. Sci. 15, 198 (2006)

4. F. Strack, R. Deutsch, Pers. Soc. Psychol. Rev. 8, 220 (2004).

5. D. Kahneman, Thinking, Fast and Slow (Farrar, Straus and Giroux, New York, 2011).

6. B. Shiv, A. Fedorikhin, J. Consum. Res. 26, 278 (1999).

7. B. J. Everitt et al., Philos. Trans. R. Soc. London Ser. B 363, 3125 (2008).

8. J. A. Bargh, M. J. Ferguson, Psychol. Bull. 126, 925 (2000).

9. W. Wood, D. T. Neal, Psychol. Rev. 114, 843 (2007).

10. A. Dijksterhuis, H. Aarts, Annu. Rev. Psychol. 61, 467 (2010).

11. J. L. Harris, J. A. Bargh, K. D. Brownell, Health Psychol. 28, 404 (2009)

12. R. C. M. E. Engels, R. Hermans, R. B. van Baaren, T. Hollenstein, S. M. Bot, Alcohol Alcohol. 44, 244 (2009)

13. T. Lancaster, L. F. Stead, Cochrane Database Syst. Rev. 2005, CD001292 (2005).

14. S. de Wit, A. Dickinson, Psychol. Res. 73, 463 (2009).

15. It is worth noting that environmental perception may be highly state-dependent. For example, people perceive slopes as being steeper when they are fatigued or encumbered or when their blood sugar levels are lower (37). We can therefore generate a more precise prediction of responses to an environment by considering the inner state of individuals acting within it, as well as the objective attributes of the environment.

16. R. V. Houten, P. A. Nau, M. Merrigan, J. Appl. Behav. Anal. 14, 377 (1981)

17. P. Rozin et al., Judgm. Decis. Mak. 6, 4 (2011).

18. L. R. Reitzel et al., Am. J. Public Health 101, 315 (2011).

19. J. Faskunger, E. Poortvliet, K. Nylund, J. Rossen, Scand. J. Nutr. 47, 26 (2003)

20. S. A. French et al., J. Occup. Environ. Med. 52 (suppl. 1), S29 (2010)

21. M. E. Benden, J. J. Blake, M. L. Wendel, J. C. Huber Jr., Am. J. Public Health 101, 1433 (2011).

22. B. Wansink, K. Van Ittersum, J. Consum. Res. 30, 455 (2003).

23. J. A. Bargh, M. Chen, L. Burrows, J. Pers. Soc. Psychol. 71, 230 (1996)

24. M. Cecchini et al., Lancet 376, 1775 (2010).

25. E. K. Papies, Curr. Obesity Rep. 1, 99 (2012).

26. C. A. Roberto, ]. Baik, J. L. Harris, K. D. Brownell, Pediatrics 126, 88 (2010)

27. T. N. Robinson, D. L. G. Borzekowski, D. M. Matheson, H. C. Kraemer, Arch. Pediatr. Adolesc. Med. 161, 792 (2007).

28. C. Moodie et al., Plain Tobacco Packaging: A Systematic Review (University of Stirling, Stirling, UK 2012).

29. M. Kutner, E. Greenberg, Y. Jin, C. Paulsen, The Health Literacy of America's Adults: Results from the 2003 National Assessment of Adult Literacy (NCES 2006-483; 
U.S. Department of Education) (National Center for Education Statistics, Washington, DC, 2006).

30. D. Spears, Economic Decision-Making in Poverty Depletes Behavioral Control (CEPS Working Paper, Center for Economic Policy Studies, Princeton University, Princeton, N], 2010); www.princeton.edu/ceps/workingpapers/ 213spears.pdf (accessed August 2012).

31. J. Williams, S. Clemens, K. Oleinikova, K. Tarvin, The Skills for Life Survey: A National Needs and Impact Survey of Literacy, Numeracy and ICT Skills (Department of Education and Skills, Norwich, UK, 2003).

32. A. Moors, J. De Houwer, Psychol. Bull. 132, 297 (2006).
33. G. ]. Hollands et al., Altering Choice Architecture to Change Population Health Behaviour: A Large-Scale Conceptual and Empirical Scoping Review of Interventions Within Micro-Environments (Univ. of Cambridge, Cambridge, 2012)

34. G. J. Hollands, A. Prestwich, T. M. Marteau, Health Psychol. 30, 195 (2011).

35. R. W. Wiers, M. Rinck, R. Kordts, K. Houben, F. Strack, Addiction 105, 279 (2010)

36. P. M. Gollwitzer, P. Sheeran, Adv. Exp. Soc. Psychol. 38, 69 (2006)

37. S. Schnall, ]. R. Zadra, D. R. Proffitt, Perception 39, 464 (2010)
Acknowledgments: We thank, H. Ziauddeen, I. Shemilt, and A. L. Kinmonth for helpful comments on a draft of this article. The Behavior and Health Research Unit of the University of Cambridge is funded by the UK Department of Health policy research program (107/0001-Policy Research Unit in Behavior and Health). The views expressed are not necessarily those of the UK Department of Health P.C.F. is supported by the Bernard Wolfe Health Neuroscience fund and by a Wellcome Trust Senior Research Fellowship in Clinical Science.

10.1126/science.1226918

\title{
PERSPECTIVE
}

\section{Fetal and Early Childhood Undernutrition, Mortality, and Lifelong Health}

\author{
Chessa K. Lutter $^{1 *}$ and Randall Lutter ${ }^{2}$
}

Child undernutrition is a major public health challenge, estimated to be responsible for 2.2 million annual deaths. Implementation of available interventions could prevent one-third of these deaths. Emerging evidence suggests that breast-feeding can lead to improvements in intelligence quotient in children and lower risks of noncommunicable diseases in mothers and children decades later. Nonetheless, breastfeeding and complementary feeding practices differ greatly from global recommendations. Although the World Health Organization recommends that infants receive solely breast milk for the first 6 months of life, only about one-third of infants in low-income countries meet this goal, just one-third of children 6 to 24 months old in low-income countries meet the minimum criteria for dietary diversity, and only one in five who are breast-fed receive a minimum acceptable diet. Although the potential effects of improved breast-feeding and complementary feeding appear large, funding for research and greater use of existing effective interventions seems low compared with other life-saving child health interventions.

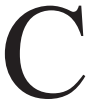
hild undernutrition is a major public health challenge and is estimated to be responsible for 2.2 million annual deaths worldwide of children under the age of 5, although full implementation of available nutrition interventions could prevent more than one-third of these deaths (1). Interventions to improve breast-feeding and complementary feeding are estimated to be the first and third most effective preventive interventions against child mortality - the second being the use of insecticide-treated bed nets to protect against malaria (2). Improved breast- feeding and other nutritional interventions aimed at children under 5 and pregnant women have substantial benefits beyond affecting mortality, including improvements in intelligence quotient (IQ) and lower risks of some noncommunicable diseases (NCDs) (3), which collectively cause $63 \%$ of deaths globally (4). Further, improved breast-feeding also has benefits in high-income countries: The social costs of low breast-feeding rates in the United States alone were recently estimated at $\$ 13$ billion annually (5).

Child undernutrition is a broad and complex phenomenon, encompassing fetal undernutrition; insufficient breast-feeding; and complementary feeding of diets low in energy-dense foods, essential fatty acids, and micronutrients. The effects of undernutrition include low birth weight and deficits in height and weight, as well as physiological outcomes later in life. The importance of these factors prompted U.S. Secretary of State Hillary Clinton to describe the benefits of improved nutrition in utero and during the first 24 months of life as providing a valuable "1000 day window of opportunity" for lifelong health and development ( 6 ).

${ }^{1}$ Pan American Health Organization/World Health Organization (PAHO/WHO), 525 23rd Street NW, Washington, DC 20037 2895, USA. ${ }^{2}$ Resources for the Future, 1616 P Street NW, Washington, DC 20036-1400, USA

*To whom correspondence should be addressed. E-mail: lutterch@paho.org

Table 1. Breast-feeding and selected maternal health outcomes. $\mathrm{Cl}$, confidence interval. A person-year is the sum of the number of years that each study participant's health condition was observed.

\begin{tabular}{|c|c|c|c|}
\hline Outcomes & Measure of breast-feeding & Effect size & Notes \\
\hline Ovarian cancer & Length of breast-feeding & $\begin{array}{l}\text { Reduced risk of ovarian cancer by } 28 \% \\
\text { for each year of breast-feeding } \\
\text { (odds ratio: } 0.72 ; 95 \% \mathrm{Cl}: 0.54 \text { to } 0.97 \text { ) }\end{array}$ & $\begin{array}{l}\text { Meta-analysis of nine studies with } 4387 \text { cancer } \\
\text { ovarian cancer cases and 10,574 controls (32) }\end{array}$ \\
\hline Breast cancer & Length of breast-feeding & $\begin{array}{l}\text { Reduced risk of breast cancer by } 4.3 \% \\
\text { for each year of breast-feeding in first } \\
\text { analysis; reduced risk of breast cancer by } \\
28 \% \text { for each year or more of breast-feeding } \\
\text { in second analysis }\end{array}$ & $\begin{array}{l}\text { First meta-analysis included } 45 \text { studies conducted } \\
\text { through 2001; second meta-analysis } \\
\text { included } 23 \text { studied published between } \\
1980 \text { and } 1998 \text { (32) }\end{array}$ \\
\hline Type 2 diabetes & Length of breast-feeding & $\begin{array}{l}\text { Reduced diabetes risk by } 4 \% ; 95 \% \mathrm{Cl}: 1 \\
\text { to } 9 \% \text { per year of breast-feeding in first } \\
\text { cohort and } 12 \% ; \mathrm{Cl}: 6 \text { to } 18 \% \text { in second cohort }\end{array}$ & $\begin{array}{l}\text { Two cohorts from a high-quality } \\
\text { longitudinal study of } 150,000 \text { parous } \\
\text { women in the U.S. (32) }\end{array}$ \\
\hline Hypertension & $\begin{array}{l}\text { Never breast-fed versus } \\
\text { exclusively breast-fed first } \\
\text { child for } \geq 6 \text { months }\end{array}$ & $\begin{array}{l}\text { Increased risk of hypertension by } 29 \% \\
\text { (hazard ratio: } 1.29 ; 95 \% \mathrm{Cl}: 1.20 \text { to } 1.40 \text { ) }\end{array}$ & $\begin{array}{l}55,636 \text { parous women in the U.S., } \\
\text { reported } 8861 \text { cases during } 660,880 \\
\text { person-years of observations }(30)\end{array}$ \\
\hline
\end{tabular}

